\title{
INTEGRANDO APPS NAS AULAS DE MUSICALIZAÇÃO INFANTIL DA ESCOLA DE ARTES - UFAM
}

\section{INTEGRANDO APPS EN LAS CLASES DE MUSICALIZACIÓN INFANTIL DE LA ESCUELA DE ARTES - UFAM}

\author{
Moreira, Dulcianne ${ }^{1}$, Regina, Freitas ${ }^{2}$, Lopes, Fernanda ${ }^{3}$, Colares, Jackson ${ }^{4}$ \\ ${ }^{1}$ Universidade Federal do Amazonas - dulciane.moreira@gmail.com \\ 2Universidade Federal do Amazonas - regina.dsfreitas@gmail.com \\ ${ }^{3}$ Universidade Federal do Amazonas - fernandapalhetalopes00@gmail.com \\ ${ }^{4}$ Universidade Federal do Amazonas - jackson.colares@gmail.com
}

\begin{abstract}
Resumo: O uso das TICs no mundo contemporâneo está presente em todos os setores da sociedade e em todos níveis de formação formal, não-formal e informal. No contexto da educação musical, as TICs têm permitido implementar diferentes ambientes de formação musical e podem estar presentes desde a educação infantil, no ensino superior e até nos estudos avançados de teoria e performance musical. Nossa pesquisa, fez um levantamento dos Apps que estão presentes no cotidiano dos alunos da Escola de Artes da UFAM, o que nos permitiu elaborar uma tabela e separá-los por categorias. $O$ trabalho leva em consideração a expansão do uso de dispositivos móveis, sua integração no ambiente educacional e a oferta de Apps para a educação musical infantil, considerando que essas tecnologias permitem que os alunos vivenciem e construam seus próprios conhecimentos, levando em conta as estratégias de interação que o professor desenvolve com os diferentes aplicativos.
\end{abstract}

Palavras-chave: TICs, APPs, Educação Musical, Musicalização.

Resumen: El uso de las TICs en el mundo contemporáneo está presente en todos los sectores de la sociedad y en todos los niveles de formación formal, no formal e informal. En el contexto de la educación musical, las TICs han permitido la implementación de diferentes entornos de formación musical y pueden estar presentes desde la educación infantil hasta la educación superior e incluso en los estudios avanzados de teoría y performance musical. Nuestra investigación empieza por medio de una encuesta para identificar Apps que están presentes en la vida cotidiana de los estudiantes de la Escuela de Artes de la "Universidade Federal do Amazonas", permitiendo la elaboración de una tabla y separarlos por categorías. El trabajo tiene en cuenta la expansión del uso de dispositivos móviles, su integración en los diferentes entornos educativos, además de la creciente oferta de Apps para la educación musical infantil, teniendo en cuenta que estas tecnologías permiten a los estudiantes experimentar y desarrollar sus propios conocimientos, además de las estrategias de enseñanza que el profesor desarrolla con la interacción de diferentes aplicaciones.

Palabras clave: TIC, aplicaciones, educación musical, musicalización. 


\title{
1. INTRODUÇÃo
}

Na contemporaneidade, o uso das Tecnologias da Informação e Comunicação - TICs está presente nas mais variadas atividades desenvolvidas pelo homem. Adquirir informação e conhecimento vai muito além da sala de aula, vencendo as barreiras de tempo e espaço, criando a necessidade de se adequar aos novos paradigmas de comunicação que interligam milhões de pessoas em tempo real. Para Campos (2007):

\begin{abstract}
"As TICs alteraram as práticas sociais e, em consequência, modificaram, e continuam modificando, a relação humana com o saber e com o poder. As inovações nas formas de assimilação, de produção, de acumulação e de transmissão do conhecimento requerem o desenvolvimento de novas competências cognitivas e relacionais". (CAMPOS, 2007, p. 81).
\end{abstract}

Para Costa (2004), as tecnologias se flexibilizaram e se adaptaram às mais diferentes situações, influenciando nos hábitos mais privados, transformando radicalmente o cotidiano, os espaços públicos, impactando, inclusive, na arte e nas relações que ela mantinha com outras áreas da atividade humana. Nosso trabalho traz algumas reflexões sobre as transformações vivenciadas a partir da integração e do uso efetivo de dispositivos de comunicação digital fixos e móveis como ferramentas que podem potencializar o processo de ensino e aprendizagem musical, e se desenvolve no contexto da Escola de Artes da UFAM, identificando e classificando Apps desenvolvidos para o ensino de música para crianças, levando em conta, principalmente, as plataformas Android e iOS (Apple). Entendemos, portanto, que as tecnologias despertam na criança o interesse por aprender, adquirir habilidades de construção de conhecimento, consolidam estratégias que aperfeiçoam sua formação inicial musical, tornando-se mais autônomo e ativo em seu processo de aprendizagem.

\section{TICS E EdUCAÇÃO MUSICAL}

Na educação musical, as TICs transformaram os processos de ensinar e aprender música, novas estratégias foram implementadas na busca por dinamizar os ambientes de formação, como resposta a uma sociedade midiatizada, que vive interligada e interage com as mais variadas tecnologias de informação e comunicação, além de uma diversidade de dispositivos eletrônicos fixos e móveis. Segundo Colares (2017 apud Salinas 1999), as possibilidades que oferecem as TIC, para o âmbito da formação, fazem que também apareçam novos tipos de usuários-alunos, caracterizados por uma nova relação com o conhecimento e com estratégias e práticas de aprendizagem que se adaptam a contextos em constantes transformações. Para Gilberto Prado (2003):

O acesso à complexidade do mundo se faz, de mais a mais, por essa intermediação tecnológica: formas de procedimento e de esquematização que se, para alguns, vão desencadear uma uniformização do mundo e dar lugar a uma perda do sensível, para outros, ao contrário, serão as ferramentas e os instrumentos necessários para se aproximar e despertar o seu "próximo", por mais longe que ele esteja. (PRADO, 2003, p. 24).

A universidade como agente de desenvolvimento de tecnologia e conhecimento tem a responsabilidade de disponibilizar recursos que venham atender às exigências geradas pela presença das TIC no contexto da sociedade e, consequentemente, no contexto educativo, ou seja, as pessoas 
apresentam necessidades educativas, sociais e emocionais de comunicar. A resposta a essas necessidades marcará, em grande medida, o êxito do sistema que estamos configurando. Colares e Brandão (2011) comentam que:

\begin{abstract}
A sociedade dos dias atuais, agora estereotipada de sociedade da informação ou multimídia, exige que as inovações atendam e facilitem as mais variadas tarefas do dia a dia, que se caracterizem pela simplicidade no manejo e pelas possibilidades de interatividade. (COLARES E BRANDÃO, 2011, p. 103).
\end{abstract}

Nesse cenário, ainda há quem diga que as metodologias e estratégias para ensinar música devem privilegiar as interações sensíveis, ou seja, aquelas vivenciadas somente pelo corpo sem qualquer mediação tecnológica, para, posteriormente, internalizar a grafia específica da música, o que cria uma dicotomização na aprendizagem musical, desconsiderando as estratégias de ensino-aprendizagem, que podem ser construídas a partir da interação e interatividade inerentes a esses dispositivos. Passos (2017, p. 22) comenta que "as tecnologias praticamente se tornaram extensões do nosso corpo, membros virtuais que alcançam horizontes inatingíveis em tempos atrás". Royo (2000) afirma que nessa contemporaneidade, quando nos referimos a música, independente do estilo ou do suporte utilizado, seja educativo ou comercial, esta encontra-se processada ou reprocessada por algum meio tecnológico, ou seja, essa midiatização pode ocorrer no momento da criação, da interpretação ou da reprodução da obra musical.

Portanto, podemos afirmar que os avanços das tecnologias digitais ampliaram as possibilidades de formação em música, desde a educação infantil até as classes mais avançadas de teoria, interpretação e performance musical. Araldi (2013) comenta que a presença das TICs na sala de aula deve trazer novas reflexões e torna-se imprescindível que a área de educação musical encontre respostas aos desafios, à influência e às transformações globais na formação musical, geradas pela integração dessas tecnologias.

\title{
3. MuSicalizaÇão Na EdUCAÇão INFANTIL
}

A música se destaca pela sua capacidade de comunicação, por se fazer presente em todas as manifestações sociais e pessoais do ser humano, desde os tempos mais remotos, quando o homem primitivo se comunicava somente através de gestos e sons rítmicos. Da mesma maneira, a criança entra em contato com o universo sonoro desde antes do nascimento, ainda no ventro da mãe, por exemplo, por meio do cantar da mãe, dos sons da natureza e de outros sons produzidos em seu entorno.

Quando entendemos que a tecnologia é o resultado da relação do homem com seu meio, esta passa a ser uma ferramenta de transformação, ou seja, responsável por romper rotinas e provocar mudanças, surgindo, portanto, como facilitadora das rotinas diárias do ser humano. Colares (2014) afirma que as técnicas e os meios disponíveis para elaboração e produção de formas e objetos artísticos, independentes do suporte, se sonoro, concreto ou digital, são elementos que condicionam a produção e a criação artística; igualmente são decisivos para entender como o homem de cada época se relaciona artisticamente com os meios de produção. 
A educação infantil, para Pacheco (2005), é um espaço em que as atitudes e as práticas educativas dos professores devem estar voltadas para a construção do conhecimento. Por outro lado, a escola deveria propiciar condições para que seus alunos possam entrar em contato com o conhecimento, promovendo o seu crescimento humano, cognitivo, psicológico e social. Os processos de desenvolvimento e de aprendizagem que se realizam nesse espaço devem considerar a forma como a criança pensa, pauta suas experiências lúdicas, faz uso de sua imaginação e criatividade para ter acesso aos conhecimentos que lhe são necessários e transformá-los em instrumentos de interação com a realidade. Oliveira (2012, pg. 6) comenta que: "de forma ativa e contínua, a aprendizagem musical integra prática, reflexão e conscientização, encaminhando a experiência para níveis cada vez mais elaborados". Nesse contexto, pensar o ensino de música na educação infantil é construir estratégias de aprendizagem por meio do fazer musical, possibilitando que a criança desenvolva, de forma diferenciada, a interpretação e a comunicação com o mundo que o cerca, expandindo sua sensibilidade estética e a criatividade. Esse fazer musical significa, portanto, musicalizar o que para Debora Oliveira (2001) é:

[...] desenvolver o senso musical das crianças, sua sensibilidade, expressão, ritmo, "ouvido musical", isso é, inseri-la no mundo musical, sonoro. O processo de musicalização tem como objetivo fazer com que a criança se torne um ouvinte sensível de música, com um amplo universo sonoro. (OLIVEIRA, 2001, p. 99.)

\section{O Programa de Extensão "Escola de Artes da UfaM"}

O programa "Escola de Artes", da Universidade Federal do Amazonas, foi criado em 2010, sob a coordenação do extinto Departamento de Artes, hoje Faculdade de Artes. Seu objetivo era ofertar à comunidade universitária e geral diferentes cursos na área das Artes. Segundo Colares e Lopes (2016), este programa foi inicialmente estruturado como um projeto de extensão, com o objetivo de oferecer cursos básicos na área das Artes: Música e Artes Visuais. Inicialmente, os cursos foram organizados como cursos livres e, na sequência, os cursos foram se estruturando com planos curriculares próprios e regulares.

Com o desenvolvimento do projeto e da regulamentação dos Programas de Extensão Universitária, por meio da Resolução no 001/2012 da Câmara de Extensão e Interiorização da UFAM, o projeto se transformou em um programa institucional de extensão, possibilitando à coordenação apresentar propostas para editais do Ministério da Educação-Secretaria de Educação Superior - (MEC/SESU), por meio do qual recebeu recursos, por duas vezes seguidas, para a estruturação dos cursos, bem como para integrar outros projetos de extensão da área de Artes. Os cursos são ministrados por alunos do curso de Licenciatura em Música e Artes Visuais, supervisionados por um professor da Faculdade de Artes, proporcionando a oportunidade de adquirir e experimentar a prática docente, além de integrar parte das atividades de disciplinas obrigatórias, como Estágio Supervisionado I e II, e o Programa de Iniciação ao Ensino - PIBID. Todas as atividades são transformadas em créditos, que podem ser utilizados para as Atividades Acadêmicas Científicas Culturais - AACC e Atividade Curricular de Extensão - ACE. 


\section{Metodologia}

Nossa pesquisa se desenvolveu no escopo da Pesquisa em Processo de Desenvolvimento de Tecnologia Educacional - PPDTE, do termo em espanhol "La Investigación Basada en Diseño en Tecnología Educativa". Essa metodologia de pesquisa deve ser entendida como um tipo de pesquisa orientada para a inovação educacional, cuja característica fundamental é a introdução de um novo produto para transformar uma determinada situação. Tem por objetivo responder a problemas concretos detectados na realidade educacional, recorrendo a teorias e modelos disponíveis para propor possíveis soluções. Para tanto, são elaborados programas, aplicativos, pacotes didáticos, materiais, estratégias didáticas etc., que são submetidos a testes e validação e, uma vez aprimorados, são reintegrados ao ambiente estudado e à realidade escolar. Compreende como produto não apenas objetos materiais (livros didáticos, programas de vídeo, aplicativos de computador, jogos de simulação), mas também processos e procedimentos (métodos de ensino, planos de organização escolar, estratégias de ensino). Segundo De Benito Crosetti; Salinas Ibáñez (2016) apud Richey, Klein y Nelson (2003), essa metodologia tem sua ênfase na produção de conhecimento com o objetivo de melhorar os processos educativos, seu desenvolvimento e avaliação.

Os procedimentos metodológicos adotados foram: 1. Levantamento de literatura sobre o tema, que nos permitiu fazer uma análise da integração das TIC no âmbito da educação musical, relacionando o estudo à prática docente, articulando os conteúdos de formação musical e as tecnologias disponíveis; 2. Como se tratava de uma pesquisa cuja temática se refere à integração e ao uso de tecnologias digitais foi construído um questionário no Google Formulários, como "internet-based survey", Cohen et al. (2011), que nos permitiu identificar os Apps mais utilizados pelos alunos do curso de Licenciatura em Música que atuavam como instrutores nos cursos de música da Escola de Artes da UFAM.

A seleção dos alunos de música foi realizada por meio de amostragem não probabilística, porque os participantes da pesquisa foram selecionados a partir de sua relação com a Escola de Artes, não por meio de um critério estatístico. A amostra foi intencional, escolhemos os elementos pertinentes da comunidade focada, a pesquisa se dirigiu a um grupo em específico para identificar o uso de Apps nas aulas de música no contexto da Escola de Artes da UFAM.

\section{Resultados}

O questionário foi respondido pelos professores da Escola de Artes, formado por um grupo misto e com quantidade igual de participantes do sexo masculino e do feminino (Graf. 1).

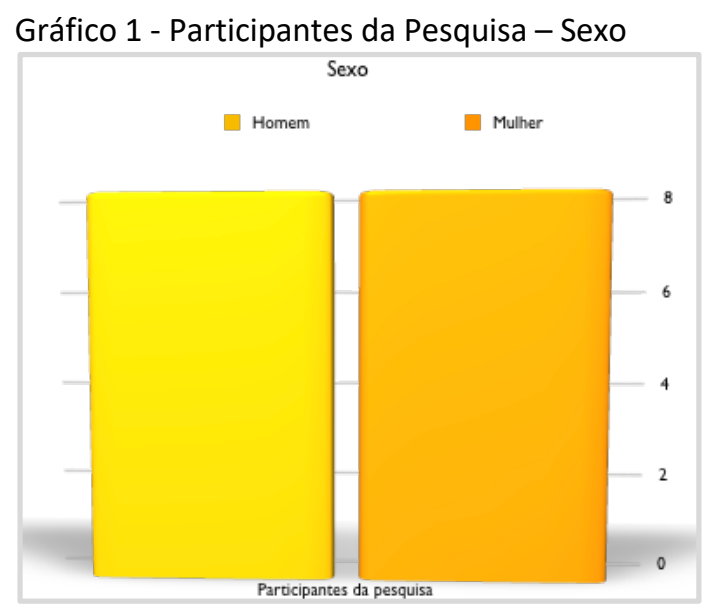

Fonte: Elaboração dos autores 
Quanto ao sistema operacional, identificamos que a plataforma Android (Graf. 2) é a mais utilizada.

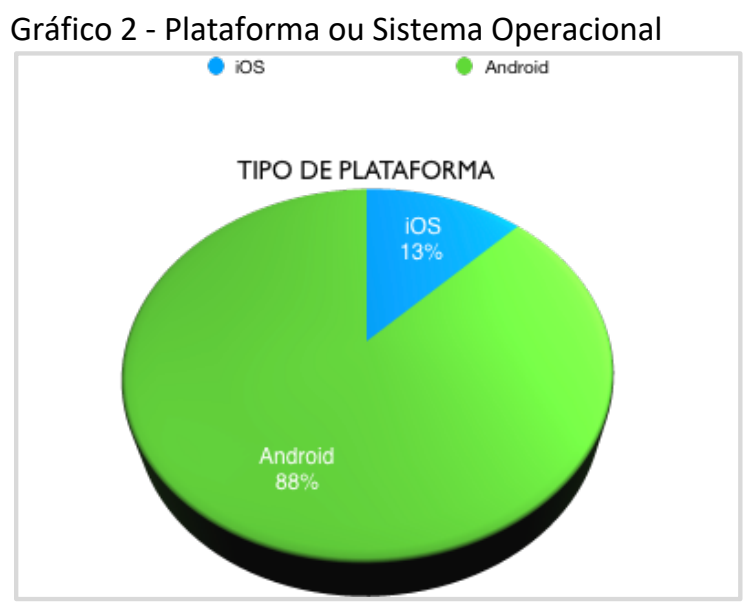

Fonte: Elaboração dos autores

Esse resultado é um espelho do que publicou Christian de la Cruz (2014) no artigo "Android es la plataforma preferida por los desarrolladores", para o sítio web FayerWayer, onde destaca que: 70\% dos desenvolvedores ocupam seu tempo na criação de aplicativos para Android. Em segundo lugar, uns $51 \%$ se dedicam ao iOS, enquanto que um respeitável terceiro lugar se dedica ao Windows Phone, o que configura $28 \%$ dos desenvolvedores (os $18 \%$ das aplicações são Modern UI). O resto se divide em desenvolvimento da web móvel com uns $15 \%$ e $11 \%$ em aplicações para BlackBerry. No Gráfico 3, temos uma lista dos aplicativos mais utilizados, com percentuais de uso. Com destaque aos gravadores de áudio, porque os alunos utilizam esses aplicativos para gravar a si mesmos e depois corrigir os erros que são percebidos nas gravações.

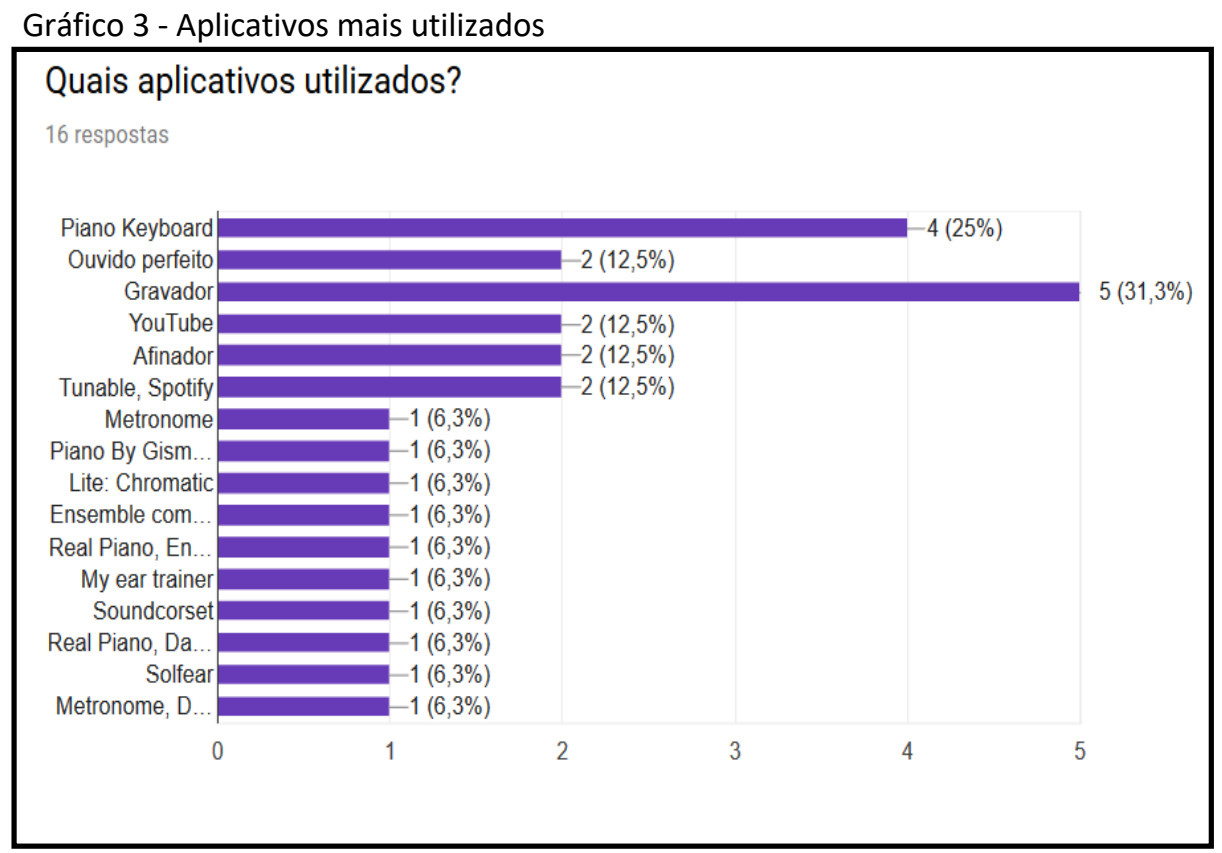

Fonte: Elaboração dos autores

Os dados levantados no questionário nos permitiram desenvolver uma tabela inicial de aplicativos em duas categorias e que estão disponíveis para as duas plataformas: Educação Musical e Produção Sonora. (Tabela 01) 


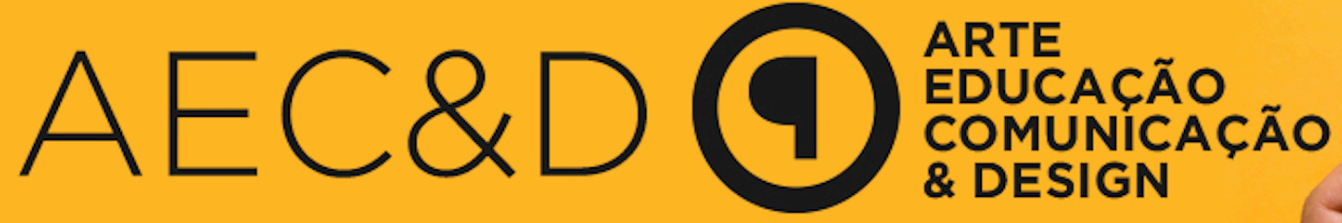

Tabela 1 - Lista de aplicativos para a Educação Musical e Produção Sonora PLATAFORMA CATEGORIAS

\begin{tabular}{|c|c|c|}
\hline PLATAFORMA & CATEGORIAS & APLICATIVOS \\
\hline \multirow{18}{*}{$\begin{array}{c}\text { IOS } \\
\text { ANDROID }\end{array}$} & \multirow{13}{*}{ Educação musical } & Piano Keybord \\
\hline & & Piano By Gismort \\
\hline & & Ensenbler Composer \\
\hline & & Lite: Chromatic \\
\hline & & Chacome \\
\hline & & Real Piano. \\
\hline & & Ouvido Perfeito \\
\hline & & My eantrainan \\
\hline & & Soundcorset \\
\hline & & Da Tuner Lite \\
\hline & & Music Notes \\
\hline & & Solfejar \\
\hline & & Tunable \\
\hline & \multirow{5}{*}{ Produção Sonora } & Gravador \\
\hline & & Youtube \\
\hline & & Afinador \\
\hline & & Spotify \\
\hline & & Metronomo \\
\hline
\end{tabular}

Fonte: Elaboração dos autores

Outro aspecto da pesquisa foi realizado com um grupo de alunos da Escola de Artes. O objetivo desse momento era verificar se, de fato, a utilização de Apps agregava na aprendizagem musical. Verificouse, de início, que uma minoria utiliza algum tipo de aplicativo como ferramenta para aprendizagem musical, por uma razão quase unânime: as crianças não possuíam dispositivos de comunicação próprios, utilizam os dispositivos dos pais e estes costumam oferecer o celular como estratégia de entreter os filhos naqueles momentos em que precisavam descansar ou realizar uma atividade mediada por outra tecnologia.

A partir disso, propomos algumas atividades tendo como finalidade contribuir para o melhoramento do ensino-aprendizagem musical. Nas aulas de musicalização, introduzimos os seguintes aplicativos: Sons para crianças, Tuhu Musical e Rhythmic Village.

Sons para crianças é um App grátis e sem anúncio oferecido pela Wismedia. O usuário pode facilmente conhecer várias coisas como animais, instrumentos, veículos, ferramentas etc., com um simples toque na tela do Smartphone ou Tablet. (Fig. 1). O App possui 65 imagens cuidadosamente projetadas e coloridas, com mais de 250 sons de fácil manuseio. (Fig. 2)

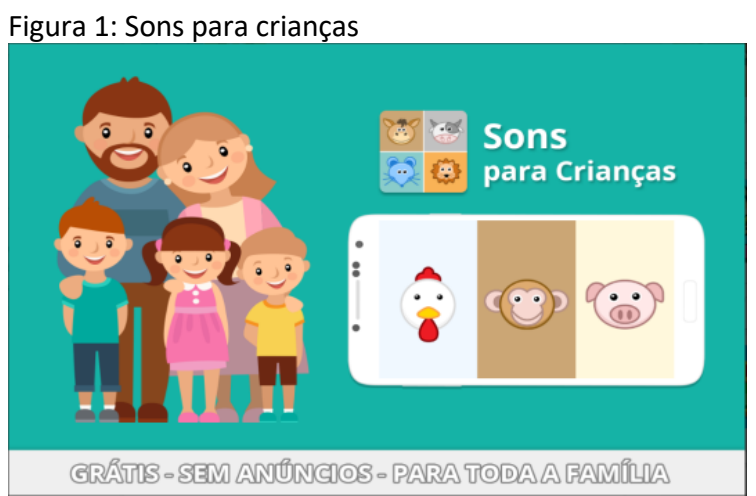

Fonte: Google Play

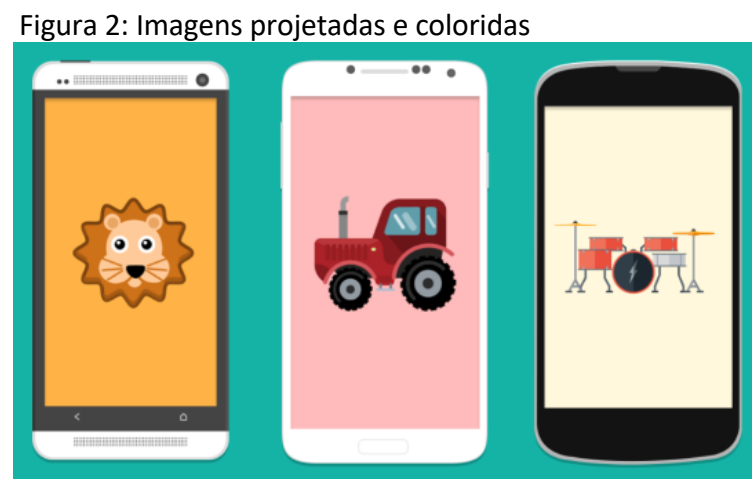

Fonte: Google Play 
Nessa atividade, abordamos sobre sons da natureza, animais, do cotidiano e até os instrumentos musicais. Na sequência, os alunos passaram a utilizar o dispositivo para relacionar e responder sobre os timbres de cada fonte sonora que era proposta.

O App Tuhu Musical foi desenvolvido como um jogo em que as crianças aprendem os fundamentos da música de forma divertida e criativa, oferece instrumentos para tocar (Fig. 3) e criar suas próprias músicas no estilo brasileiro (Fig.4). De acordo com o site do desenvolvedor: "Este APP integra o Programa "Brasil de Tuhu", que promove a educação musical no Brasil através de concertos interativos em escolas públicas, um portal com diferentes conteúdos didáticos e ciclos de capacitação para educadores".

Fig.3 - Tela de início

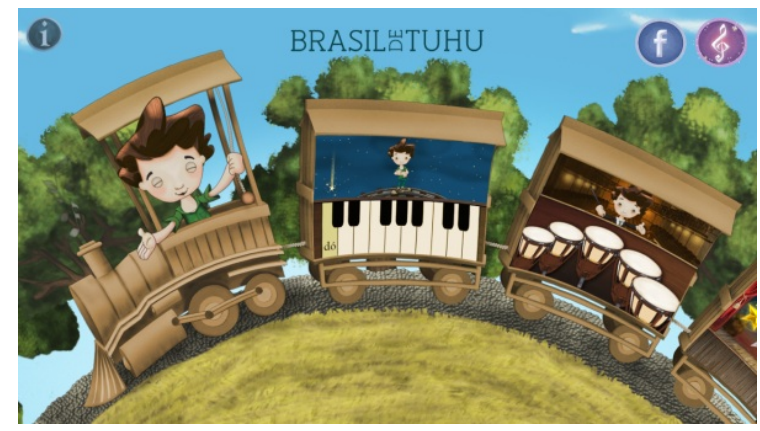

Fonte: Google Play
Fig.4 - Sala de concerto

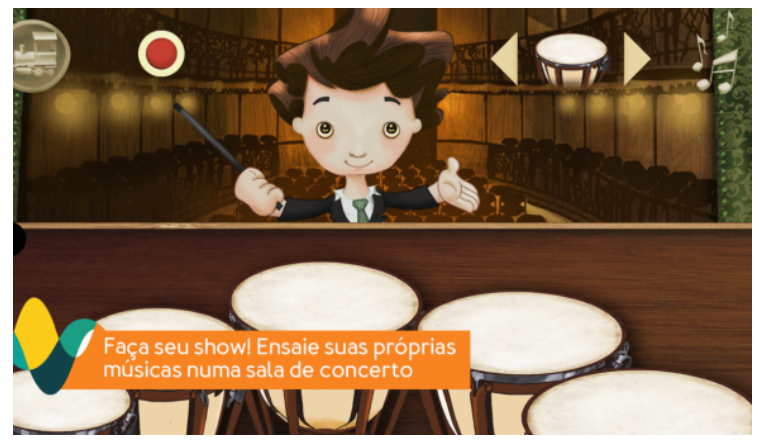

Fonte: Google Play

Nesse aplicativo, seguindo as instruções de teste, as crianças tocaram a música "Carneirinho Carneirão", clicando nas estrelinhas que apareciam conforme a música (Fig.5). A atividade ajudou as crianças a terem noções de ritmo e melodia, trabalhou a memória e a percepção da sequência apresentada pelas estrelas (Fig.6)

Fig.5 - Música no estilo brasileiro

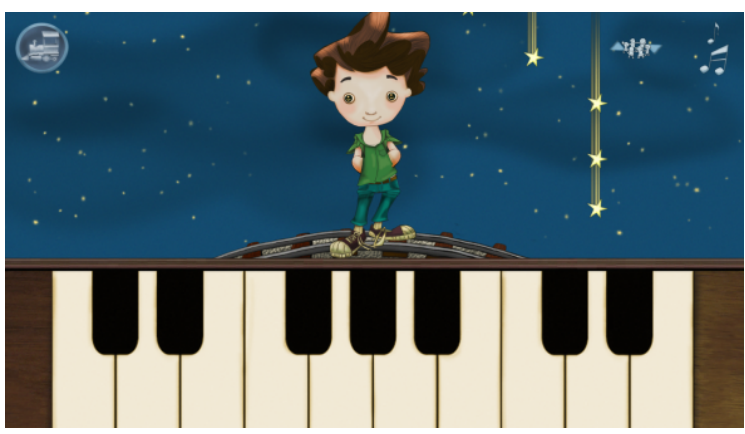

Fonte: Google Play
Fig. 6 - Sequência das estrelas para memorização

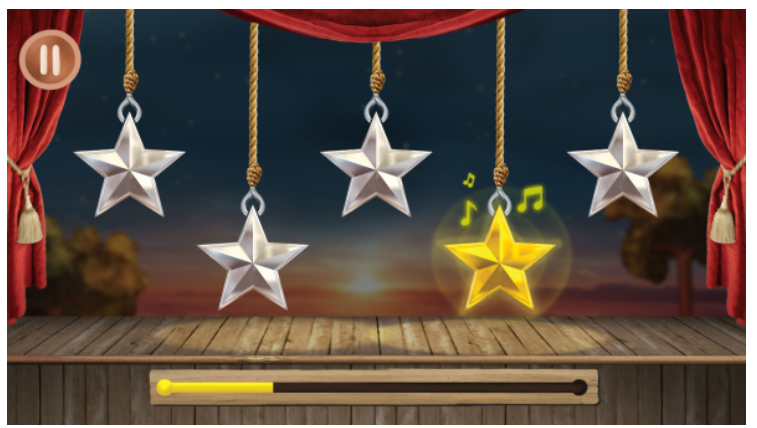

Fonte: Google Play

O App Rhythmic Village utiliza a metáfora de viagem exploratória, partindo de uma aventura, que é descobrir as notas musicais, bem como aprender a base da leitura rítmica com instrumentos de percussão (Fig. 8). A versão de avaliação é gratuita, mas limitada. A versão completa é paga e com inúmeras funções e atividades.

Com esse aplicativo, os alunos puderam, ainda que fosse a versão de teste, ouvir e acompanhar as propostas rítmicas e interagir de forma bastante fácil. $\mathrm{O}$ jogo vai aumentando de nível, acrescentando novos ritmos, propondo sempre um novo desafio a ser vencido. 


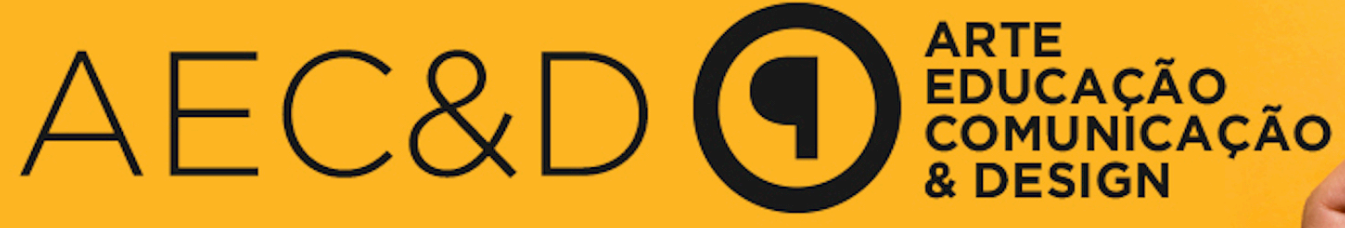

Fig. 7 - Tela de início

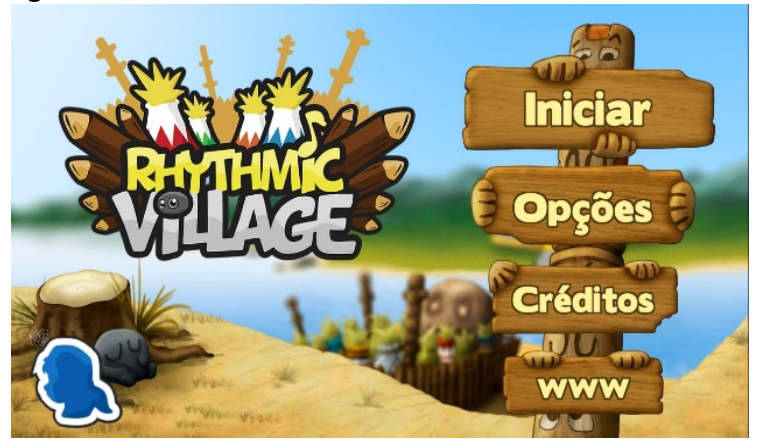

Fonte: Google Play
Fig. 8 - Atividade de ritmo

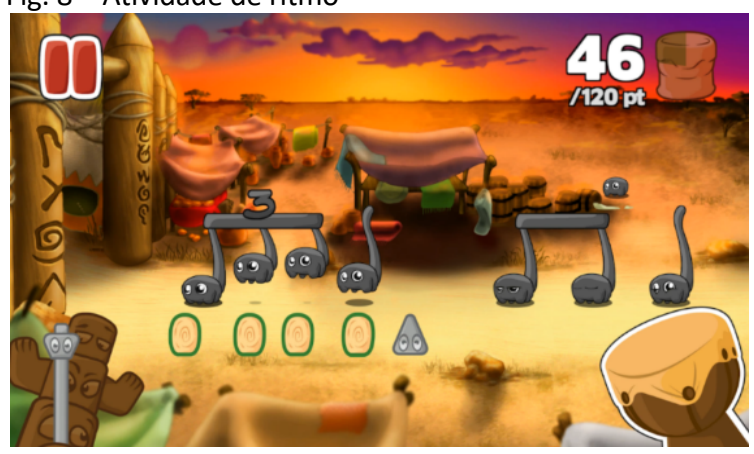

Fonte: Google Play

Segundo o desenvolvedor, algumas características podem ser destacadas:

- Aprendizagem baseada em videojogos, introduzindo instrumentos de percussão;

- É possível jogar com instrumento reais (baquetas, bloco de madeira, tambor, bongos etc.), ativando a opção de microfone;

- Desafios rítmicos possuem fundamento pedagógico;

- Se apresenta como sistema de aprendizagem inovador para a leitura rítmic.

\title{
7. CONSIDERAÇÕES FINAIS
}

A pesquisa demonstrou que os alunos utilizam efetivamente Apps como estratégia para aprender música e fazem usos dos mesmos para distintos conteúdos. Identificamos, ainda, que estes dispõem de algum tipo de dispositivo de comunicação, com acesso à internet, o que os possibilita acessar os conteúdos específicos e de seu interesse, ainda que em momentos pontuais. Portanto, o uso de aplicativos musicais pode ser especialmente produtivo, possibilitando o desenvolvimento do processo de ensino e aprendizagem de maneira significativa, motivando a participação dos alunos nas atividades de forma mais efetiva e potencializando a aprendizagem musical. Nas palavras de Gouveia (2015):

\begin{abstract}
As tecnologias inseridas no contexto educativo, não devem ter como sua principal função a de ensinar, mas sim a de criar condições de aprendizagem. Desta forma, o professor deve assumir o papel de criar ambientes de aprendizagem e facilitar o processo de desenvolvimento intelectual do aluno. Os alunos cresceram num novo ambiente tecnológico, com uma cultura própria e irão viver as suas vidas num contexto mais exigente, competitivo e complexo.
\end{abstract}

Portanto, o uso e a integração das TICs e de Apps nas aulas de música cria, para os professores, a necessidade de formação continuada e auto formação e, para os alunos, disponibiliza outras fontes de informação e novas possibilidades de aprendizagem.

\section{REFERÊNCIAS}

ARALDI, J. Transformações tecnológicas e desafios na formação e atuação de professores de música. Hipertextus Revista Digital, v. 11, p. 1-22, 2013. Disponível em: <http://www.hipertextus.net>. Acesso em: 23/4/2017.

DE BENITO CROSETTI, B.; SALINAS IBÁÑEZ, J. M. La Investigación Basada en Diseño en Tecnología Educativa. Revista Interuniversitaria de Investigación en Tecnología Educativa, v. 0, n. 1, p. 44-59, 2016. Disponível em: <http://revistas.um.es/riite/article/view/260631>. Acesso em: 27/3/2018. CAMPOS, S. B. DE. O Impacto das Tecnologias no Cotidiano Escolar : Um saber necessário na educação contemporânea. PerCursos, v. 8, p. 77-89, 2007. Disponível em: 
$<$ http://www.periodicos.udesc.br/index.php/percursos/article/view/1515/1279>. Acesso em:

30/5/2018.

CHRISTIAN DE LA CRUZ. FayerWaver. Disponível em:

$<$ https://www.fayerwayer.com/2014/07/android-es-la-plataforma-preferida-por-los-

desarrolladores/>. Acesso em: 20/3/2018.

COHEN, L.; MANION, L.; MORRISON, K. Research Methods in Education. 2011.

COLARES, J. FaArtes virtual : Um Modelo de Ambiente Virtual para o Ensino de Artes na Universidade Federal do Amazonas. Anais do Congresso Nacional da Associação Brasileira de Educação Musical, v. 2, n. 2003, 2017. Disponível em:

<http://abemeducacaomusical.com.br/conferencias/index.php/congresso2017/cna/paper/view/272 2/1376>. Acesso em: 22/2/2018.

COLARES, J.; BRANDÃO, R. Planejamento e produção de recursos didáticos interativos: Processos e procedimentos para integração dos objetos sonoros. Sociedade do conhecimento e meio ambiente: sinergia científica gerando desenvolvimento sustentável. Primeira ed., p.51-8, 2011. Manaus: Reggo Edições.

COLARES, J.; LOPES, F. Educação musical \& tecnologia no contexto da escola de artes da UFAM: curso interativo para flauta doce - exercícios graduados e repertório amazônico. In: R. Roig-Vila (Org.); Tecnología, innovación e investigación en los procesos de enseñanza-aprendizaje. $1^{\mathrm{a}}$ ed, p. 294303, 2016. Barcelona: Octaedro.

COSTA, C. O belo, a percepção estética e o fazer artístico. $1^{\underline{a}}$ ed. São Paulo: Moderna, 2004. GOUVEIA, A. Educação Musical e as Novas Tecnologias. Ferramentas de Apoio ao Docente de Música, 2015. Instituto Politécnico de Coimbra. Disponível em:

<https://comum.rcaap.pt/bitstream/10400.26/11701/1/ANA_GOUVEIA.pdf>. Acesso em: 30/5/2018. OLIVEIRA, C. B. N. DE. A prática do canto coral infantil como processo de musicalização, 2012.

Universidade Estadual de Campinas. Disponível em:

<http://repositorio.unicamp.br/bitstream/REPOSIP/284386/1/Oliveira_CleodicelesBrancoNogueirad e_M.pdf>. Acesso em: 26/6/2018.

OLIVEIRA, D. A. DE. Musicalização na educação infantil. ETD. Educação Temática Digital, v. 3, no 1, p. 98-108, 2001. Disponível em:

<https://www.ssoar.info/ssoar/bitstream/handle/document/10529/ssoar-etd-2001-1-oliveiramusicalisacao_na_educacao_infantil.pdf?sequence=1>. Acesso em: 20/9/2018.

PACHECO, E. G.; MARIA, S. Educação musical na educação infantil : uma investigação-ação na formação e nas práticas das professoras, 2005. Universidade Federal de Santa Maria. Disponível em: <https://repositorio.ufsm.br/bitstream/handle/1/6794/EDUARDO PACHECO.pdf >. Acesso em: 30/7/2018.

PASSOS, L. As possibilidades dos apps como ferramentas de aprendizagem musical. 1a ed. Novas Edições Acadêmicas, 2017.

PRADO, G. Arte Telemática, dos intercâmbios pontuais aos ambientes virtuais multiusuário. Itaú Cultu. ed. São Paulo, 2003.

ROYO, C. F. Proyectos telemáticos y aprendizaje musical. Revista electrónica de LEEME, no 1997, p. 1-8, 2000. Disponível em: <http://musica.rediris.es/leeme/revista/fuertes00.pdf >. Acesso em: $18 / 2 / 2017$. 